\title{
EFEITO DO NÚMERO DE OPERAÇÕES MECANIZADAS DE NIVELAMENTO DE SOLO SOBRE OS COMPONENTES DE RENDIMENTO E ALTURA DA LÂMINA DE ÁGUA NA CULTURA DO ARROZ IRRIGADO
}

\author{
Cleiton José Ramão, ${ }^{1 *}$ Elódio Sebem, ${ }^{1}$ Lúcio de Paula Amaral ${ }^{1}$, Alexandre Russini ${ }^{2}$, Edgar Salis Brasil Neto, ${ }^{2}$ \\ Rogério Rodrigues de Vargas, ${ }^{2}$ Marcelo Silveira de Farias ${ }^{3}$ \\ 1 Programa de Pós-Graduação em Agricultura de Precisão, Universidade Federal de Santa Maria \\ 2 Universidade Federal do Pampa, Campus Itaqui, 97650-000, Itaqui, Brasil. \\ 3 Departamento de Ciências Agronômicas e Ambientais, Universidade Federal de Santa Maria, Campus de Frederico Westphalen, \\ 98400-000, Frederico Westphalen, Brasil.
}

*E-mail: cleitonramao80@hotmail.com

\section{RESUMO}

Este trabalho teve como objetivo analisar o efeito do número de operações mecanizadas de nivelamento da superfície do solo sobre os componentes de rendimento e altura da lâmina de água na cultura do arroz irrigado. O estudo foi realizado em uma área subdividida em dois talhões de 15 hectares, sendo conduzida sob sistema de cultivo mínimo. As variações no número de operações de nivelamento do solo, constituíram de uma e duas operações, utilizando um conjunto mecanizado composto de trator e plaina niveladora hidráulica. Foi utilizado um grid com intensidade amostral de um hectare, sendo analisados a altura média da lâmina de água e os seguintes componentes de rendimento: população de plantas, número de panículas, produtividade e grãos inteiros (rendimento de indústria). A produtividade de arroz e a altura média da lâmina de água não foram influenciadas pelo número de operações mecanizadas de nivelamento do solo. A maior correlação observada referente à produtividade foi o número de panículas por área, mas sem interferência significativa no rendimento final da cultura. Também, pode-se observar baixa correlação entre rendimento de indústria e produtividade, em ambos os tratamentos. Portanto, a realização de uma segunda operação de nivelamento do solo, nas condições em que o experimento foi realizado, não se justifica economicamente, pois o incremento de produção não cobre os custos da segunda operação.

Palavras-chave: Mecanização agrícola. Preparo de solo. Custo de produção. Agricultura de precisão.

\section{Introdução}

$\mathrm{O}$ arroz irrigado é uma cultura que se caracteriza pela exigência em água durante seu ciclo, dependendo do sistema de irrigação utilizado [1]. O sistema de irrigação adotado no estado do Rio Grande do Sul é predominantemente por inundação, necessitando da aplicação de grandes volumes de água [2], sendo muito exigente em nivelamento de solo e manejo de água. Ainda, os autores ressaltam que a Região da Fronteira Oeste do Rio Grande do Sul, apesar do elevado potencial produtivo do arroz, apresenta menor disponibilidade hídrica e, consequentemente maior demanda de água, quando comparado a outras regiões do Estado. Os estudos de Machado et al. [3] revelaram que os diferentes sistemas de cultivo se comportam de maneira semelhante no que se refere ao consumo de água. Quando se trata de nivelamento de solo, independentemente do método de preparo é necessário realizar o nivelamento da superfície, o que permite a uniformização da altura da lâmina de água e o controle eficiente de plantas daninhas [4]. As operações de nivelamento superficial do solo consistem de uma atividade de rotina dentro das áreas de várzea, na qual visa à uniformidade do micro relevo existente na área, favorecendo o manejo da irrigação e o controle de plantas daninhas, durante o ciclo da cultura. Conforme Wopereis et al. [5], o nivelamento do solo, evita o escoamento superficial contínuo de água para os drenos, menor perda de água por infiltração através das taipas, por já estarem consolidadas.

Para a realização da operação de nivelamento do solo, utilizam-se plainas niveladoras hidráulicas acopladas à barra de tração ou ao sistema hidráulico de engate aos três pontos dos tratores agrícolas. Essa operação possui elevado rendimento operacional, porém requer elevada demanda de potência. Por se caracterizar uma operação que exige um número indeterminado de passadas em função do terreno e da demanda energética 
significativa, impacta diretamente e de forma variável nos custos de produção agrícola.

Atualmente este equipamento tem substituído as operações de gradagem pesada e leve, minimizando o revolvimento do solo. Comumente, os agricultores realizam duas operações de nivelamento, porém em muitas situações poderia ser realizada apenas uma operação, reduzindo significativamente o custo operacional.

Os custos de produção na agricultura e, em particular, na lavoura orizícola, apresentam a cada safra um incremento considerável, principalmente no que diz respeito à energia elétrica e ao combustível. O combustível é responsável por movimentar o parque de máquinas que a lavoura orizícola necessita para a realização das operações, que vão desde o processo de preparo do solo até a colheita da cultura. Dentre os itens que mais impactam no custo de produção, encontram-se as máquinas agrícolas (tratores e colhedoras) que correspondem a $23,85 \%$ do custo total das despesas [6].

Para Nöller [7], com os custos de produção em constante elevação, o produtor busca novas tecnologias para aumentar sua eficiência produtiva, e com isso se manter na atividade. Ainda conforme o autor, tal tecnologia pode ser obtida com ferramentas de Agricultura de Precisão (AP), que considera a variabilidade detalhada dentro de cada área produtiva, visando o uso adequado dos insumos e, também como uma ferramenta de gestão dentro da propriedade, buscando otimizar a eficiência técnica e econômica do processo produtivo. Assim, a técnica de manejo localizado, busca conciliar as variáveis ambientais, agronômicas e a produtividade, visando maximizar o uso dos recursos disponíveis, na tentativa de reduzir os custos de produção [8].

A AP em arroz irrigado ainda é pouco estudada quando comparada às culturas de sequeiro, como soja e milho, porém, é considerada uma das culturas que mais responde ao manejo, tanto em fertilidade quanto em preparo de solo [9]. Ainda, o sucesso para altas produtividades de arroz depende de uma perfeita sincronia no manejo, havendo forte dependência entre os fatores: preparo de solo, irrigação, fertilidade e manejo fitossanitário. Devido, a necessidade de saber qual o melhor manejo, as ferramentas de AP podem oferecer importantes modelos agronômicos, o que potencializará as atividades dentro da propriedade, proporcionando redução dos custos por área cultivada.

O manejo diferenciado de nivelamento do solo pode ocasionar incremento de produtividade, devido à correção do micro relevo, a qual poderá propiciar maior uniformidade na altura da lâmina de água, com posteriores melhorias nos componentes de rendimento da cultura. Neste contexto, este trabalho teve como objetivo analisar o efeito do número de operações mecanizadas de nivelamento da superfície do solo sobre as componentes de rendimento e altura da lâmina de água na cultura do arroz irrigado.

\section{Metodologia}

O trabalho foi conduzido em uma área de cultivo comercial de arroz irrigado, localizada no município de Itaqui, na Fronteira Oeste do Rio Grande do Sul (Figura 1).

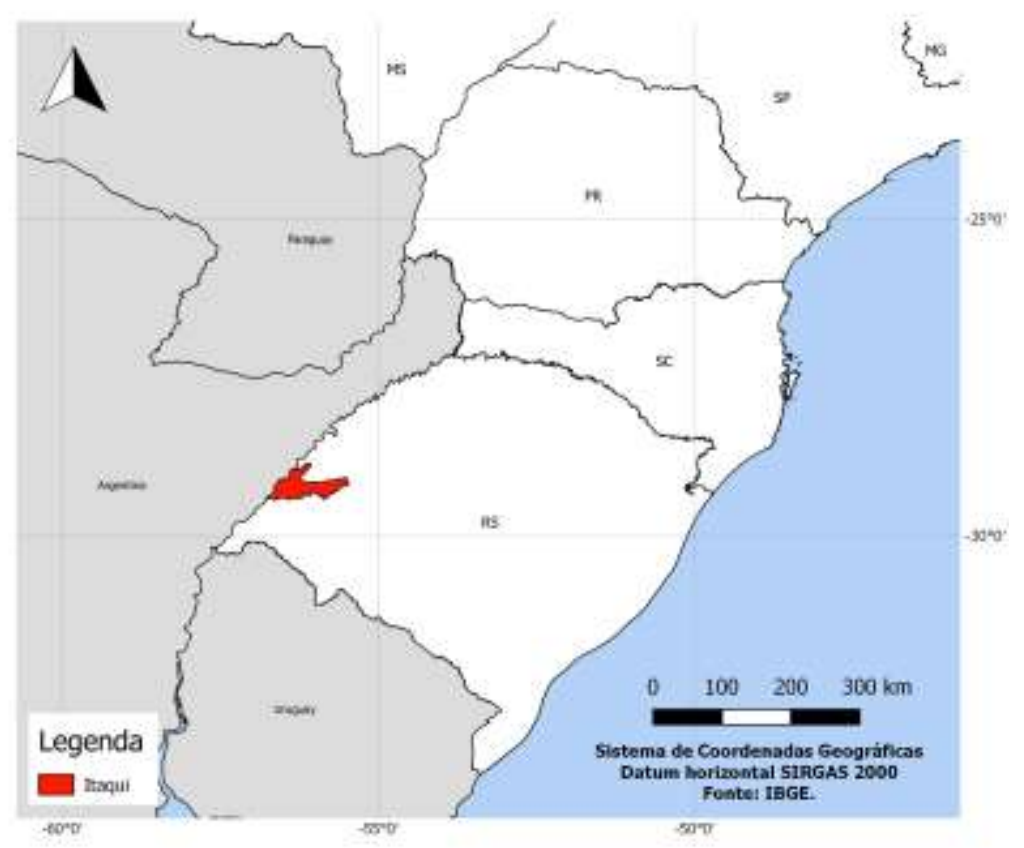

Figura 1 - Localização do município de Itaqui, na Fronteira Oeste do Rio Grande do Sul, Brasil.

A área foi cultivada com arroz irrigado na safra anterior, sendo utilizada com pecuária de corte no período de entressafra. Após esse período, foram realizadas duas operações de gradagem leve para uniformizar as irregularidades do solo, oriundas do cultivo anterior. Na sequência, realizaram-se as operações de nivelamento do solo e a construção de curvas de nível. Para semeadura, utilizou-se a cultivar BR IRGA 409, na densidade de $100 \mathrm{~kg} \mathrm{ha}^{-1}$, sendo a adubação realizada em taxa fixa, com dose de $286 \mathrm{~kg} \mathrm{ha}^{-1}$ com formulação (4-17-27), mais $80 \mathrm{~kg} \mathrm{ha}^{-1}$ de nitrogênio em cobertura. $O$ manejo da cultura seguiu as recomendações técnicas, visando à homogeneidade nos tratos culturais a fim de diminuir a variabilidade e a interferência nos parâmetros avaliados.

Foram utilizadas duas áreas (talhões) de 15 hectares (Figura 2), totalizando 30 hectares manejadas sob sistema de 
cultivo mínimo. O número de operações de nivelamento da superfície do solo foi alterado, constituído de uma e duas operações de nivelamento, onde se fez o uso de um conjunto mecanizado constituído de trator e plaina niveladora hidráulica acoplada a barra de tração.

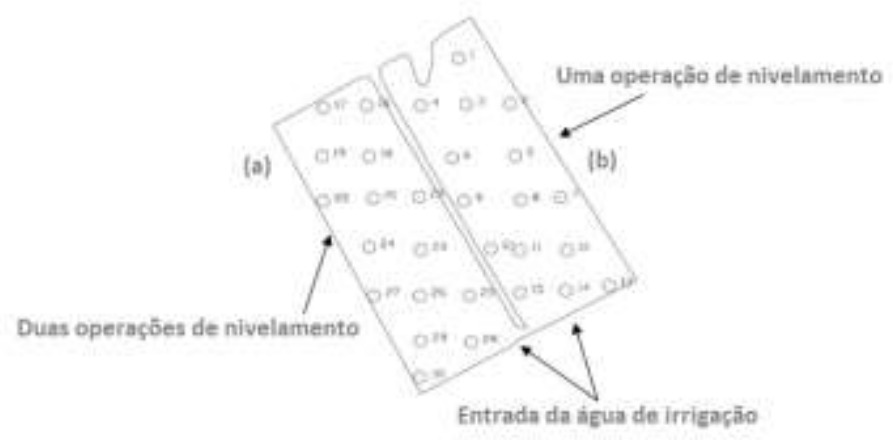

Figura 2 - Croqui da área experimental com seus respectivos pontos de coleta: (a) duas operações de nivelamento da superfície do solo; e (b) uma operação de nivelamento.

As áreas foram georreferenciadas com uso de um receptor GNSS com rastreamento apenas dos sinais da constelação americana GPS, com precisão posicional variando de 5 a $10 \mathrm{~m}$ (Código C/A), sendo posteriormente gerado um grid amostral para identificação dos pontos de coleta. Foi adotado uma malha quadrangular, com intensidade amostral de um ponto por hectare para ambas às áreas, contendo os respectivos pontos amostrais. Segundo Cherubin [10] os pontos das malhas amostrais comercialmente utilizadas nas áreas manejadas com agricultura de precisão no Sul do Brasil são espaçados em 100 m (uma unidade amostral por hectare) a $175 \mathrm{~m}$ (uma unidade amostral a cada 3 hectares), baseadas por razões de ordem econômica e prática. Nos pontos amostrais, a partir da emergência das plântulas, realizou-se a contagem do número de plantas por metro quadrado e posterior estimativa da população de plantas por hectare. Cada ponto amostral consistiu de uma unidade amostral, composta por quatro sub-unidades de $0,25 \mathrm{~m}^{2}$ cada.

Após a entrada da água de irrigação na área, a cada 20 dias foram realizadas amostragens, compostas de quatro sub-unidades da altura de lâmina de água por ponto amostral, obtendo-se a altura de lâmina média. As coletas foram realizadas até o estágio de maturação fisiológica, perfazendo duas coletas na fase vegetativa e duas na fase reprodutiva, permitindo desta forma, gerar um mapa da altura média da lâmina de água ao longo do ciclo da cultura. No período de maturação fisiológica também foi realizada a amostragem para estimativa da produtividade, composta por quatro sub-unidades de $0,25 \mathrm{~m}^{2}$, por ponto amostral. Essas amostras foram trilhadas de forma manual, pesadas e a umidade dos grãos corrigida para 13\%. Durante a amostragem, foi quantificado o número de panículas, para determinação do rendimento de grãos inteiros.

Os dados foram submetidos à análise estatística descritiva, com a intenção de verificar as medidas de posição, dispersão, assimetria e forma das distribuições dos dados, com auxílio do software estatístico Action Stat Pro. Os parâmetros estatísticos determinados foram: média, mediana, desvio padrão, valor máximo, valor mínimo, coeficientes de variação (CV\%), assimetria (Cs) e de curtose (Ck). Para testar a normalidade dos dados, foi usado o teste Kolmogorov-Smirnov ao nível de 5\% de probabilidade, Schneider et al. [11]. Para a verificação de correlação entre os dados, foi realizada a análise de correlação linear simples de Pearson ( $\mathrm{p}<0,05)$. A interpolação dos dados foi realizada por meio da Krigagem ordinária, considerando 30 pontos amostrais, na qual foram gerados os mapas para as seguintes variáveis: altura média da lâmina de água, população de plantas, número de panículas e produtividade. Utilizou-se para gerar a malha amostral e os mapas, o programa computacional Sistema Agropecuário CR - Campeiro $7^{\circledR}$, desenvolvido pelo Laboratório de Geomática, do Departamento de Engenharia Rural da Universidade Federal de Santa Maria. As variáveis em relação ao número de operações de nivelamento de solo também foram submetidas à análise de variância (ANOVA) e ao teste de Tukey, de comparação de médias, em nível de 5\% de significância.

\section{Resultados e discussões}

Os dados obtidos apresentaram distribuição normal, e posteriormente foram correlacionados pela Correlação de Pearson. $\mathrm{O}$ resultado do teste de normalidade para as variáveis analisadas está apresentado na Tabela 1.

Tabela1- Resultado do teste de normalidade Kolmogorov-Smirnov para as variáveis analisadas.

\begin{tabular}{lcccc}
\hline Variável & Dcalc & P-valor & $\begin{array}{c}\text { Dcrítico } \\
\mathbf{( 0 , 0 5 ; 3 0 )}\end{array}$ & Interpretação \\
\hline Pop. & 0,105 & 0,531 & 0,241 & Dist. Normal \\
LA & 0,092 & 0,735 & 0,241 & Dist. Normal \\
NP & 0,127 & 0,239 & 0,241 & Dist. Normal \\
GI & 0,070 & 0,966 & 0,241 & Dist. Normal \\
Prod. & 0,077 & 0,917 & 0,241 & Dist. Normal \\
\hline
\end{tabular}

Pop: População de plantas $/ \mathrm{m}^{2}$; LA: Lâmina d'água média (cm); NP: Panícula/m², GI: Grãos inteiros (\%); Prod.: Produtividade ( $\mathrm{kg} \mathrm{ha}^{-1}$ ). Interpretação: Dcalc $<$ Dcrítico, aceita hipótese de normalidade dos dados ao nível de 5\% de probabilidade de erro.

A análise descritiva dos componentes de rendimento e altura de lâmina de água está apresentada na Tabela 2.

Segundo Carvalho [12] a distribuição de frequência simétrica, onde a média, moda e mediana apresentam o mesmo valor é de difícil ocorrência na prática. Para Andriotti [13], os 
valores de coeficiente de assimetria variando entre $-0,2$ e $+0,2$ podem ser considerados simétricos. Desta forma todas as variáveis são simétricas, exceto lâmina de água média. Quando os valores estão situados na faixa entre - 1,0 e - 0,2 ou 0,2 e 1,0, a assimetria é considerada fraca, como é o caso desta última variável, e enviesada a direita (por ser positiva). Se os valores forem inferiores a $-1,0$ ou superiores a 1,0, a assimetria é considerada forte. Esta condição sugere que os dados possuem distribuição de frequência próxima à da distribuição normal, por serem simétricos ou de assimetria fraca.

Tabela 2 - Análise descritiva dos componentes de rendimento de arroz irrigado e altura da lâmina de água em cultivo realizado no município de Itaqui, RS.

\begin{tabular}{|c|c|c|c|c|c|c|c|c|}
\hline Variável & Média & Mediana & $\begin{array}{l}\text { Desvio } \\
\text { Padrão }\end{array}$ & Máx ${ }^{(1)}$ & Mín & $\mathrm{CV}(\%)^{(3)}$ & $\mathrm{Cs}^{(4)}$ & $\mathrm{Ck}^{(5)}$ \\
\hline Pop. & 171,2 & 170,5 & 33,90 & 234,0 & 97 & 19,8 & $-0,03$ & $-0,40$ \\
\hline NP & 487,0 & 498,5 & 45,8 & 586 & 390 & 9,4 & $-0,20$ & $-0,40$ \\
\hline Prod. & 10472 & 10395 & 1080 & 12707 & 8293 & 10,30 & $-0,16$ & $-0,39$ \\
\hline GI & 63 & 63 & 1,60 & 65,70 & 59,8 & 2,50 & $-0,20$ & $-0,70$ \\
\hline LA & 3,13 & 3,12 & 1,40 & 6,70 & 0,80 & 44,60 & 0,50 & 0,20 \\
\hline
\end{tabular}

Legenda: (1) Valor Máximo; (2) Valor Mínimo; (3) Coeficiente de Variação; (4) Coeficiente de Assimetria; (5) Coeficiente de Curtose.

Pop: População de plantas $/ \mathrm{m}^{2}$; LA: Lâmina d'água média (cm); NP: Panicula/m²; GI: Grãos inteiros (\%); Prod.: Produtividade (kg ha ${ }^{-1}$ ).

Com relação ao coeficiente de curtose, Andriotti [13] descreve o grau de achatamento de uma curva em relação a uma normal, tomada com padrão. A partir desta informação pode-se afirmar que a população de plantas, número de panículas, produtividade e grãos inteiros apresentaram curva platicúrtica $(\mathrm{Ck}$ $>0,263$ ), ou seja, quando os dados apresentam uma medida de curtose maior que a da distribuição normal, e altura da lâmina de água curva leptocútica $(\mathrm{Ck}<0,263)$, ou seja, quando os dados apresentam uma medida de curtose menor que a da distribuição normal. Quanto maior o valor de curtose, maior será a concentração de valores da distribuição em torno do centro da mesma. A curva de distribuição mediana é chamada de mesocúrtica $(\mathrm{Ck}=0,263)$, sendo esta a própria curva de distribuição normal, quanto mais às curvas leptocúrtica e planicúrtica se aproximarem desta, maior será a probabilidade dos dados apresentarem normalidade, como é o caso das variáveis em análise.

Quanto ao coeficiente de variação (CV), o maior valor observado refere-se à altura da lâmina de água (44\%) e população de plantas $(19,8 \%)$, valores considerados médios, enquanto as demais variáveis apresentaram baixo coeficiente de variação, conforme Warrick e Nielsen [14], na qual consideram: baixo (CV $<12 \%$ ), médio $(12 \%<\mathrm{CV}<60 \%)$ e alto ( $\mathrm{CV} \geq 60 \%)$. Pode-se inferir que a maior variabilidade observada na variável altura da lâmina de água, deve-se a alterações não corrigidas no micro relevo, decorrentes do preparo de solo realizado, principalmente quando se reduz o número de operações de nivelamento de solo. A população de plantas está de acordo com o proposto por Marzari [15], a qual relata que a população ideal de plantas deve estar entre 150 a 380 por metro quadrado, variando em função da densidade de semeadura.

O número de panículas está de acordo com as recomendações da SOSBAI [9], sendo que conforme descrito por Durigon [8], é um componente de rendimento muito variável, na qual pode ser influenciado, por exemplo, pelo excesso de água no início da cultura, na qual contribui para menor perfilhamento, consequentemente menos número de panículas. Franco [16] descreve que ocorre uma tendência de aumento no número de panículas com o aumento da densidade.

Já os valores de produtividade e o percentual de grãos inteiros são influenciados por diversos fatores, dentre eles a altura da lâmina de água, sendo que Rosso [17] observou maiores valores de produtividade em menores alturas de lâmina de água.

Os resultados obtidos a partir da análise de correlação de Pearson, entre os atributos de produção de arroz estão apresentados na Tabela 3. Observa-se que no manejo envolvendo uma operação de nivelamento do solo, alguns dos componentes 
apresentaram correlação significativa. As maiores correlações positivas com a produtividade foram quanto ao número de panículas $/ \mathrm{m}^{2}(88 \%)$, seguido da média da altura de lâmina de água $(61,8 \%)$

Tabela 3 - Análise de correlação dos atributos de produção de arroz irrigado em Itaqui, RS, com uma operação de nivelamento da superfície do solo.

\begin{tabular}{lccccc}
\hline & Pop. & LA & NP & GI & Prod. \\
\hline Pop. & 1 & & & & \\
LA & $-0,268^{\mathrm{ns}}$ & 1 & & & \\
NP & $-0,127^{\mathrm{ns}}$ & $0,407^{\mathrm{ns}}$ & 1 & & \\
GI & $0,372^{\mathrm{ns}}$ & $-0,054^{\mathrm{ns}}$ & $0,037^{\mathrm{ns}}$ & 1 & \\
Prod. & $-0,167^{\mathrm{ns}}$ & $0,618^{*}$ & $0,882^{*}$ & $-0,031^{\mathrm{ns}}$ & 1 \\
\hline
\end{tabular}

Legenda: *Correlação de Pearson significativa $(\rho \leq 0,05) .{ }^{n s}$ Correlação de Pearson não significativa $(\rho \leq 0,05)$; Pop.: População de plantas $/ m^{2}$; LA: Lâmina d'água média (cm); NP: Panícula/m²; GI: Grãos inteiros (\%); Prod.: Produtividade (kg $\left.h a^{-1}\right)$

Segundo a Sociedade Sul-Brasileira de Arroz Irrigado (SOSBAI) [9], o número de panículas $/ \mathrm{m}^{2}$ é um dos principais fatores que apresentam relação direta com a produtividade e com altura de lâmina de água, sendo suficiente para obter ótimas produtividades, porém com lâmina acima de $10 \mathrm{~cm}$ reduz o número de perfilhos, favorecendo o acamamento da cultura, comportamento semelhante ao observado por Rosso [17]. Os valores do número de panículas $/ \mathrm{m}^{2}$ obtidos com uma operação de nivelamento estavam dentro do recomendado pela SOSBAI [9], onde $47,0 \%$ dos pontos amostrados possuíam mais de 480 panículas $/ \mathrm{m}^{2}$. Durigon [18], observou que correlações da produtividade de arroz irrigado com a população de plantas e número de panículas é uma ferramenta importante para auxiliar na definição de unidades de manejo localizado na área.

A média de altura da lâmina de água se manteve entre 2,0 e $6,7 \mathrm{~cm}$ em $87,0 \%$ da área do experimento. Também se observou correlação entre o número de panículas com a altura média da lâmina de água $(40,0 \%)$, embora essa correlação não seja significativa. $\mathrm{O}$ resultado demonstra a ocorrência de um número de panículas esperado nas áreas onde a altura da lâmina de água ficou com valores médios entre 4,0 a $7,0 \mathrm{~cm}$, ou seja, altura recomendada para um bom desenvolvimento de plantas. Isso corrobora com o exposto por Furlani [19], onde a lâmina de água de $15,0 \mathrm{~cm}$ reduziu o perfilhamento e o número de colmos e, consequentemente, o número de panículas, ocorrendo o contrário para as lâminas de água compreendidas entre 5,0 e $10,0 \mathrm{~cm}$ de profundidade.

A população de plantas teve uma correlação negativa de $16,0 \%$ com a produtividade embora não significativa. Ocorreu um baixo estabelecimento inicial da cultura, ficando aproximadamente $50,0 \%$ da área em estudo com densidade entre 97 a 150 plantas $/ \mathrm{m}^{2}$, onde o recomendado seria de 150 a 300 plantas $/ \mathrm{m}^{2}$ [9]; corroborando como descrito por Marzari [15].

No que se refere à correlação de grãos inteiros com a produtividade, esta foi considerada baixa $(-3,0 \%)$ e não significativa, principalmente por influência da cultivar utilizada. A cultivar BR IRGA 409, se caracteriza geneticamente pelo potencial produtivo e pela alta qualidade dos grãos, o que favorece um alto percentual de grãos inteiros, fator este agregador de valor ao produto final [20].

A maior correlação negativa observada, porém, não significativa $(-26,0 \%)$, foi entre a população de plantas e a altura de lâmina de água, situação que se explica pela maior irregularidade do terreno, o que propicia desuniformidade na deposição das sementes no solo. Referente às duas operações de nivelamento do solo, esta correlação positiva aumentou para $58,0 \%$, entre a população de plantas e a lâmina de água (Tabela 4).

Tabela 4 - Análise de correlação dos atributos de produção de arroz irrigado em Itaqui, RS, com duas operações de nivelamento da superfície do solo.

\begin{tabular}{cccccc}
\hline & Pop. & LA & NP & GI & Prod. \\
\hline Pop. & 1 & & & & \\
LA & $0,582^{*}$ & 1 & & & \\
NP & $0,343^{\text {ns }}$ & $-0,105^{\text {ns }}$ & 1 & & \\
GI & $0,101^{\text {ns }}$ & $0,023^{\text {ns }}$ & $0,061^{\text {ns }}$ & 1 & \\
Prod. & $0,067^{\text {ns }}$ & $-0,293^{\text {ns }}$ & $0,813^{*}$ & $0,112^{\text {ns }}$ & 1 \\
\hline
\end{tabular}

Legenda: *Correlação de Pearson significativa $(\rho \leq 0,05) .{ }^{n s}$ Correlação de Pearson não significativa ( $\rho \leq 0,05)$; Pop.: População de plantas $/ m^{2}$; LA: Lâmina d'água média (cm); NP: Panícula/m²; GI: Grãos inteiros (\%); Prod.: Produtividade (kg $\left.h a^{-1}\right)$.

Esta correlação positiva entre a população de plantas e a altura da lâmina de água pode ser explicada pelo fato da superfície do solo, após duas operações de nivelamento, permitir melhor germinação das sementes e não permitir a formação de microbacias de acúmulo de água, o que é prejudicial durante o estabelecimento inicial da cultura, e da mesma forma por permitir a formação de uma lâmina de irrigação uniforme.

A correlação de $34,0 \%$, embora não significativa, entre a população de plantas e o número de panículas $/ \mathrm{m}^{2}$, apresentado na Tabela 4, deve-se ao fato de que o número médio de plantas $/ \mathrm{m}^{2}$ contabilizou valores acima de 150 plantas, tendo como valor máximo 234 plantas $/ \mathrm{m}^{2}$ na área que passou por duas operações de nivelamento. Essa população permite elevar o potencial produtivo da cultura, levando-se em consideração que cada planta emite de dois a três perfilhos potencialmente produtivos, garantindo um número aproximado de 600 panículas $/ \mathrm{m}^{2}$. Os valores obtidos no trabalho demonstram que mais de $73,0 \%$ dos pontos amostrados estavam com valores superiores a 480 panículas $/ \mathrm{m}^{2}$.

Durigon [8], em experimento conduzido em área sistematizada em nível, encontrou correlação negativa de panículas $/ \mathrm{m}^{2}$ com a produtividade e a altura da lâmina de água, o qual obteve leituras da altura de lâmina de água de até $31,5 \mathrm{~cm}$. Ainda, neste mesmo estudo, o excesso de água contribuiu para o menor perfilhamento e número de panículas $/ \mathrm{m}^{2}$, reduzindo 
consideravelmente a produtividade da cultura. Isso vem ao encontro com os resultados deste trabalho, onde a correlação entre o número médio de panícula $/ \mathrm{m}^{2}$ e a produtividade foi de $81,0 \%$. Estes valores demonstram que a produtividade responde positivamente em função do adequado número de panículas por área. Freitas [21] e Fageria [22] consideraram o aumento do número de panículas por unidade de área, como fator determinante para o aumento da produtividade de arroz irrigado.

Em ambos os tratamentos, ocorreram correlações entre o número de panículas e a produtividade no valor de $88,0 \%$ e $81,0 \%$ para uma e duas operações, respectivamente. Desta forma, podese inferir que o número de panículas consiste no principal indicador de produtividade da cultura. Nas condições de campo, o número de panículas por área é influenciado por diversos fatores, tais como, uso de sementes de qualidade e alto vigor, qualidade de semeadura, densidade de sementes, variedade utilizada e altura da lâmina de irrigação [23].

Quanto à altura média da lâmina de água nos dois tratamentos, verificou-se que com duas operações de nivelamento do solo ocorreu melhor uniformidade na distribuição espacial, sendo a variação de $1,4 \mathrm{~cm}$ a $4,75 \mathrm{~cm}$, demonstrando boa uniformidade de nivelamento. Já, na área onde foi realizada apenas uma operação de nivelamento, os valores de altura de lâmina de água variaram de $0,8 \mathrm{~cm}$ a $6,7 \mathrm{~cm}$, conforme demonstrado na Figura 3.
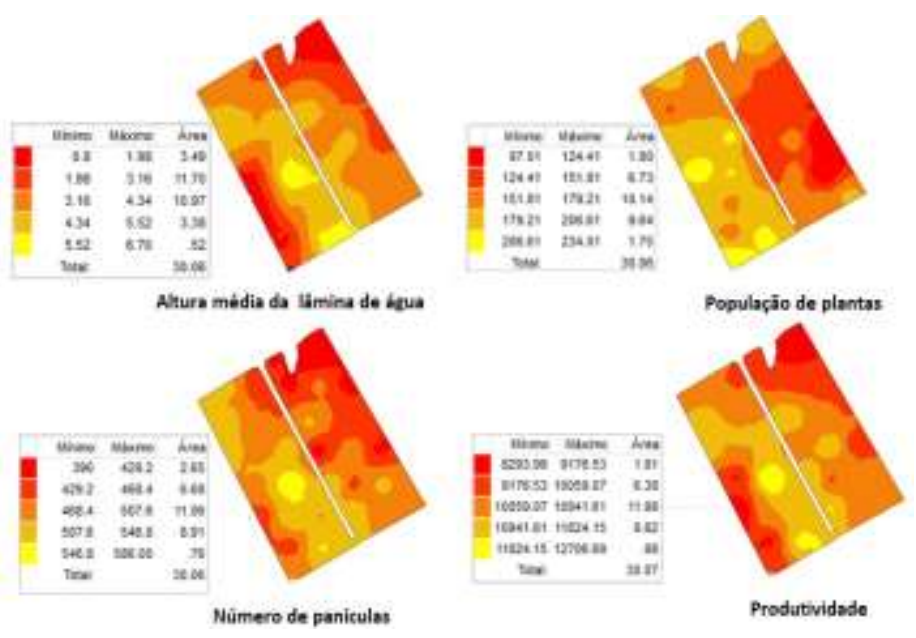

Figura 3 - Variabilidade espacial da altura da lâmina de água média $(\mathrm{cm})$, população de plantas $\left(\mathrm{m}^{2}\right)$, número de panículas $/ \mathrm{m}^{2}$ e produtividade $\left(\mathrm{kg} \mathrm{ha}^{-1}\right)$, para uma e duas operações de nivelamento em cultivo de arroz irrigado, Itaqui, RS.

No que se refere às correlações significativas com a produtividade, dentre os atributos de produção avaliados, obtevese significância para a altura média da lâmina de água e para o número médio de panículas por área em uma operação de nivelamento e, para o número de panículas por área em duas operações de nivelamento da superfície do solo. A diferença nas alturas de lâmina de água pode proporcionar maior influência do clima na cultura, principalmente pela oscilação da temperatura [24].

Ao analisar a Tabela 5, pode-se observar diferença na população de plantas, sendo que duas operações de nivelamento do solo favoreceram o estabelecimento da cultura, ou seja, maior número de plantas $/ \mathrm{m}^{2}$.

Tabela 5 - Análise estatística dos atributos de produção avaliados para uma e duas operações mecanizadas de nivelamento da superfície do solo em cultivo de arroz irrigado, Itaqui, RS.

\begin{tabular}{lcc}
\hline \multirow{2}{*}{ Variáveis } & \multicolumn{2}{c}{ Operações de nivelamento do solo } \\
\cline { 2 - 3 } & Uma operação & Duas operações \\
\hline População (plantas $\left./ \mathrm{m}^{2}\right)$ & $148,5^{\mathrm{b}}$ & $193,8^{\mathrm{a}}$ \\
Lâmina de água média $(\mathrm{cm})$ & $3,6^{\mathrm{a}}$ & $2,7^{\mathrm{a}}$ \\
Panículas (panículas/m²) & $469,6^{\mathrm{b}}$ & $504,4^{\mathrm{a}}$ \\
Grãos inteiros (\%) & $62,3^{\mathrm{b}}$ & $63,7^{\mathrm{a}}$ \\
Produtividade $\left(\mathrm{kg} \mathrm{ha}{ }^{-1}\right)$ & $10382,4^{\mathrm{a}}$ & $10561,9^{\mathrm{a}}$ \\
\hline
\end{tabular}

Legenda: *Médias seguidas pela mesma letra na linha não diferem pelo teste de Tukey, a 5\% de significância.

A partir dos dados apresentados na Tabela 5, pode-se inferir que o número de panículas diferiu em função do número operações de nivelamento do solo, apresentando um número maior de panículas no sistema que envolve duas operações de nivelamento. No que se refere à média de grãos inteiros, também apresentou diferença entre os dois tratamentos, destacando-se um acréscimo de 1,4\% para as áreas que tiveram duas operações de nivelamento da superfície.

Como há diferença entre cultivares, quanto a qualidade industrial dos grãos Canellas [25], consideram que o manejo da cultura é um fator que altera o rendimento de grãos inteiros. Dentre estes, o teor de água dos grãos, entre 18 e $25 \%$, no momento da colheita, favorece a obtenção de percentuais elevados de grãos inteiros [26]. A melhor distribuição espacial de plantas favorece a maturação fisiológica uniforme onde, segundo a SOSBAI [9], a cultura apresenta uma capacidade elástica, compensando a falta de plantas através da emissão de um número maior de perfilhos por planta.

Neste sentido, a maioria dos agricultores opta por fazer duas operações de nivelamento do solo, porém com base nos resultados deste trabalho, com apenas uma operação de nivelamento poderia reduzir de forma considerável o custo operacional, bem como aumentar a área trabalhada utilizando o mesmo conjunto mecanizado. A segunda operação de nivelamento proporcionou, um incremento de produtividade de $179,5 \mathrm{~kg} \mathrm{ha}^{-1}$ $\left(3,59\right.$ sacas ha $\left.^{-1}\right)$ em relação à área onde foi realizada apenas uma operação de nivelamento. 


\section{Conclusões}

A produtividade de arroz irrigado não foi influenciada pelo número de operações de nivelamento da superfície do solo, com plaina niveladora hidráulica.

A maior correlação observada foi do número de panículas $/ \mathrm{m}^{2} \mathrm{com}$ a produtividade, porém sem interferência no rendimento de grãos inteiros.

O aumento de produtividade decorrente de uma segunda operação de nivelamento não se justificaria economicamente, nas condições em que o experimento foi realizado.

\section{EFFECT OF THE NUMBER OF MECHANIZED SOIL LEVELING OPERATIONS ON THE YIELD COMPONENTS AND HEIGHT OF THE WATER LEVEL IN IRRIGATED RICE FIELDS}

ABSTRACT: The following research aimed to analyze the effect of the number of mechanized operations of leveling of the soil surface on the yield components and height of the water level in the irrigated rice. The study was carried out in an area subdivided into two plots of 15 hectares, being conducted under minimum cropping system. The variations in the number of soil leveling operations consisted of one and two operations, using a mechanized set consisting of tractor and hydraulic leveler. A grid with sample intensity of one hectare was used, and the average height of the water level and the following yield components were analyzed: plant population, number of panicles, productivity and whole grains (industry yield). The rice yield and mean height of the water level were not influenced by the number of mechanized soil leveling operations. The highest correlation observed for productivity was the number of panicles per area, but without significant interference in the final yield of the crop. Also, a low correlation between industry yield and productivity can be observed in both treatments. Therefore, a second soil leveling operation, under the conditions which the experiment was carried out, is not economically justified because the increase in production does not cover the costs of the second operation.

Keywords: Agricultural mechanization. Soil preparation. Production cost. Precision agriculture.

\section{Informações adicionais:} Ramão.

Este artigo faz parte da dissertação do autor Cleiton José

\section{Referências}

[1] SMITH, M. C. et al. Water use estimates for various rice production systems in Mississippi an Arkansas, Irrigation Science, Vol. 25, n. 2, p. 141-147, 2007.

[2] PINTO, M. A. B. et al. Produtividade de arroz irrigado por aspersão em terras baixas em função da disponibilidade de água e de atributos do solo, Pesquisa Agropecuária Brasileira, Vol. 51, n. 9, p. 1584-1593, 2016.

[3]MACHADO, S. L. et al. Consumo de água e perdas de nutrientes e de sedimentos na água de drenagem inicial do arroz irrigado, Ciência Rural, Vol. 36, n. 1, p. 65-71, 2006.

[4] STONE, L. F.; SILVA, J. G. Cultivo do Arroz Irrigado no estado do Tocantins. Embrapa Arroz e Feijão: Sistemas de Produção, n. 3, 2004.

[5] WOPEREIS, M. C. S. et al. Water use efficiency of flooded rice fields. IValidation of the soil-water balance model SAWAH, Agricultural Water Management. Columbus, Vol. 26, p. 277-289, 1994.

[6] IRGA. Instituto Rio Grandense do Arroz. Custo de produção médio ponderado de arroz irrigado no Rio Grande do Sul - Safra 2014/2015. Disponível em: <http://www.irga.rs.gov.br/upload/20150827150914custo_jan_2015_safra_2014_ 15_em_analise.pdf>. Acesso em: 09 out. 2017.

[7] NÖLLER, D. S. Agricultura de precisão na cultura do arroz irrigado (Oryza sativa L.) em áreas de solo sistematizadas e não sistematizadas. 2012. 97 p. Dissertação (Programa de Pós-Graduação em Engenharia Agrícola - Mestrado) Universidade Federal de Santa Maria, Santa Maria. 2012.

[8] DURIGON, R. Aplicação de técnicas de manejo localizado na cultura do arroz irrigado (Oryza sativa L.). 2007. 149 p. Tese (Programa de Pós-Graduação em Engenharia Agrícola -Doutorado) - Universidade Federal de Santa Maria, Santa Maria. 2007.

[9] SOSBAI. Sociedade Sul-Brasileira de Arroz Irrigado. Arroz Irrigado: Recomendações Técnicas para o Sul do Brasil; Bento Gonçalves, 2014. 192p.

[10] CHERUBIN, M. R. Eficiência de malhas amostrais utilizadas na caracterização da variabilidade espacial de fósforo e potássio, Ciência Rural, Vol. 44, n. 3, p. 425-432, 2014.

[11] SCHNEIDER, P. R.; SCHNEIDER, P. S. P.; SOUZA, C. A. M. Análise de regressão aplicada à Engenharia Florestal. 2 ed. FACOS/UFSM: Santa Maria, 2009. 294p.

[12] CARVALHO, J. R. P.; SILVEIRA, P. M.; VIEIRA, S. R. Geoestatística na determinação da variabilidade espacial de características químicas do solo sob diferentes preparos, Pesquisa. Agropecuária. Brasileira. Vol. 37; p. 1151-1159, 2002

[13] ANDRIOTTI, J. L. S. Fundamentos de Estatística e Geoestatística. São Leopoldo: Ed. Unisinos, 2003. 165 p.

[14] WARRICK, A. W.; NIELSEN, D. R. Spatial variability of soil physical properties in the field. In: HILLEL, D. (Ed.). Applications of soil physics. New York: Academic Press, 1980.

[15] MARZARI V. et al. População de plantas, dose de nitrogênio e aplicação de fungicida na produção de arroz irrigado, Ciência Rural. Santa Maria, Vol.37, n.2, p. $330-336,2007$

[16] FRANCO, D. F. et al. Arranjo espacial de plantas e contribuição do colmo principal e dos perfilhos na produção de grãos de arroz (Oryza sativa L.), Revista Brasileira de Agrociência, Pelotas, Vol. 17, n. 1-4, p. 32-41, 2011.

[17] ROSSO, R. B. Influência da altura de lâmina de água sob o desempenho da produção na cultura do arroz irrigado. 2014. 80p. Dissertação (Programa de Pós- 


\section{.}

Graduação em Engenharia Agrícola - Mestrado) - Universidade Federal de Santa Maria, Santa Maria. 2014.

[18] DURIGON, R. et al. Correlações entre atributos químicos do solo e atributos da cultura e da produtividade do arroz irrigado, Ciência Rural, Vol. 39, n. 9, p. 2629-2633, 2009.

[19] FURLANI, J. E. et al. Épocas de início da inundação do solo e altura da lâmina d'água em arroz irrigado, Bragantia, Vol. 54, n. 2, p. 413-418, 1995.

[20] CASTRO, E. M. et al. Qualidade de grãos em arroz. Santo Antônio de Goiás: Embrapa Arroz e Feijão, 1999. Disponível em: <https://www.agencia.cnptia.embrapa.br/Repositorio/circ_34_000fxellcv702wyiv 80soht9hyuxkqdv.pdf>. Acesso em 18 set. 2017.

[21] FREITAS, J. G. et al. Resposta de cultivares de arroz irrigado ao nitrogênio. Scientia Agrícola, Vol. 58, n. 3, p. 573-579, 2001.

[22] FAGERIA, N. K.; SANTOS, A. B.; CUTRIM, V. A. Produtividade de arroz irrigado e eficiência de uso do nitrogênio influenciadas pela fertilização nitrogenada, Pesquisa Agropecuária Brasileira, Vol.42, n.7, p. 1029-1034, 2007.

[23] ALONSO, A. S.; SANTOS, A. B.; GOMES, A. S. Cultivo de Arroz Irrigado no Brasil. Pelotas: Embrapa Clima Temperado, 2005. Disponível em: <https://sistemasdeproducao.cnptia.embrapa.br>. Acesso em: 19 dez. 2017.

[24] STEINMERTZ, S. et al. Efeito da altura da lâmina de irrigação na temperatura da água e do solo em arroz irrigado. In: VII Congresso Brasileiro de Arroz Irrigado, 2011, Camboriú. Anais... Camboriú: Pallotti, 2011. p. 469-472.

[25] CANELLAS, L. P.; SANTOS, A. G.; MARCHEZAN, E. Efeito de práticas de manejo sobre o rendimento de grãos e a qualidade industrial dos grãos em arroz irrigado, Ciência Rural, Vol. 27, n. 3, p. 375-379, 1997.

[26] MARCHESAN, E.; GODOY, O. P.; FILHO, J. M. Relações entre épocas de semeadura, de colheita e rendimento de grãos inteiros de cultivares de arroz irrigado, Pesquisa Agropecuária Brasileira, Vol. 28, n. 7, p. 843-848, 1993. 